\title{
LINGUAGEM E GÊNERO SOCIAL: CONTRIBUIÇÕES DA ANÁLISE CRÍTICA DO DISCURSO E DA LINGÜÍSTICA SISTÊMICO-FUNCIONAL
}

\author{
(Language and gender: contributions from critical discourse \\ analysis and systemic functional linguistics)
}

Débora de Carvalho Figueiredo

(Programa de Pós-Graduação em Ciências da Linguagem - Unisul - SC)

\section{Introdução}

Nas últimas décadas, a intersecção entre linguagem e gênero social tem sido explorada por várias/os lingüistas aplicadas/os (e.g. CAMERON, 1992, 1995, 2002; ECKERT; MCCONNEL-GINET, 2003; HOLMES; MEYERHOFF, 2003; WODAK, 1997; HEBERLE; OSTERMANN; FIGUEIREDO, 2006), interessadas/os no papel da linguagem e do discurso na construção de representações, relações, papéis e identidades de gênero em distintos contextos socioculturais onde a linguagem é utilizada e produzida. As abordagens teórico-metodológicas adotadas por essas/es pesquisadoras/es são as mais diversas, desde a Sociolingüística Interacional, a Análise de Discurso de linha francesa e a Análise Crítica do Discurso (ACD). Nesse artigo, defendo o uso dos modelos teóricos e metodológicos propostos pela Análise Crítica do Discurso e pela Lingüística Sistêmico-Funcional (LSF) (HALLIDAY, 2004) como ferramentas conceituais e analíticas para investigar e explicar, de uma perspectiva social crítica, as representações discursivas sobre o corpo e a identidade feminina em revistas para mulheres. Para a ACD, o uso da linguagem é visto como prática social, simultaneamente constituindo (i) identidades sociais, (ii) relações sociais, e (iii) sistemas de conhecimento e crença (FAIRCLOUGH, 2001). Esses três aspectos constitutivos do discurso estão ligados à visão multifuncional da linguagem proposta pela Lingüística Sistêmica Funcional (LSF), a teoria lingüística de base adotada por quase todos as/os analistas críticas/os do discurso. Segundo Fairclough, a LSF é bastante adequada para a ACD por estar "profundamente interessada na relação entre linguagem e outros elementos e aspectos da vida social, e [por] sua abordagem à análise lingüís- 
tica de textos [ser] sempre orientada para o caráter social dos textos" (FAIRCLOUGH, 2003a, p. 5). Quanto à relação entre linguagem e gênero social, como as pesquisas nessa área focalizam o modo como a linguagem intermedeia, mantém ou muda práticas e identidades sociais, tanto a ACD quanto a LSF constituem suportes teóricos e metodológicos bastante apropriados para investigar, por exemplo, através de textos midiáticos sobre o corpo, o aspecto semiótico das práticas sociais voltadas para a disciplina e o controle do corpo na modernidade tardia, assim como as estruturas sociais mais amplas que definem o potencial de significados que pode ser construído em eventos sociais específicos (ou, numa veia lingüística, nos textos) que constituem e representam o corpo e as identidades de gênero na modernidade tardia.

Para tanto, esse artigo está organizado nas seguintes seções: 2) Identidades, na qual trago aportes dos campos da antropologia, sociologia e estudos do discurso para pensar a centralidade atual do conceito de identidade para o campo das ciências sociais, suas relações com processos discursivos simbólicos e com a formação e alteração de identidades de gênero na pósmodernidade; 3) Análise crítica do discurso, na qual descrevo a abordagem discursiva que norteia as interpretações textuais realizadas nesse artigo; 4) Lingüiśtica sistêmico funcional, na qual introduzo a teoria lingüística de base que fornece suporte teórico e metodológico para a linha de análise de discurso aqui adotada; 5) Linguagem e gênero nas perspectivas da ACD e da LSF, na qual ilustro como textos midiáticos podem ser analisados a partir dos aportes teóricos e metodológicos apresentados nas seções anteriores, interpretando-os como artefatos culturais historicamente situados, que refletem e constroem práticas e estruturas sociais mais amplas; e 6) Comentários finais.

\section{Identidades}

Segundo Woodward (2000), a identidade tornou-se uma questão central nas discussões contemporâneas, especialmente no que diz respeito às reconstruções globais de identidades nacionais e étnicas (e.g. servos e croatas, turcos e curdos, judeus e palestinos) e do surgimento dos "novos movimentos sociais" (feminista, gay, lésbico, etc.) preocupados com a reafirmação de identidades pessoais e culturais. 
A identidade é tanto simbólica quanto social. O social e o simbólico referem-se a processos diferentes, porém necessários para a construção e a manutenção das identidades. O social diz respeito às práticas e relações sociais, enquanto que o simbólico diz respeito aos recursos utilizados para dar sentido a essas práticas e relações sociais (e.g. como justificamos a inclusão ou a exclusão de membros em um grupo). As distintas posições de identidade, assim como as restrições sobre quem pode assumir que identidades sociais, são produzidas tanto por sistemas simbólicos (e.g. linguagem) quanto por sociais (práticas e relações sociais) (WOODWARD, 2000).

Woodward sugere que, para entendermos como a identidade funciona precisamos, antes de mais nada, conceituá-la e definir suas dimensões. Para investigarmos a identidade precisamos examinar os sistemas classificatórios que moldam a forma como as relações sociais são organizadas e divididas. Nesse sentido, a autora sugere que comecemos examinando a forma como a identidade e a diferença integram o "circuito da cultura" e como são forjadas a partir de representações simbólico-discursivas.

O "circuito da cultura" é um esquema conceitual sobre a formação da identidade desenvolvido por Paul du Gay et al (1997). Segundo esse conceito, "para se obter uma plena compreensão de um texto ou artefato cultural, é necessário analisar os processos de representação, identidade, produção, consumo e regulação" (WOODWARD, 2000, p. 68). Como se trata de um circuito, é possível começar em qualquer ponto, uma vez que não estamos diante de um processo linear, seqüencial; as divisões entre os momentos do circuito são de natureza metodológica e não ontológica, isto é, todas as etapas estão ligadas entre si. A representação diz respeito aos sistemas simbólicos (verbais, visuais, etc.) que produzem significados sobre o mundo, incluindo identidades sociais. Os produtos culturais e as identidades a eles associadas são produzidos, tanto técnica quanto culturalmente, para atingir os consumidores potenciais que se identificarão (ao menos, isso é o que o mercado espera) com eles. Através de suas representações, os artefatos culturais (no caso do corpo, podemos citar como exemplos de artefatos culturais as roupas e acessórios, os produtos cosméticos, assim como os serviços que atuam no controle da forma do corpo - dietas alimentares, programas de condicionamento físico, procedimentos cirúrgicos) têm efeitos sobre a regulação da vida social, sobre as identidades a eles associadas e sobre a articulação entre sua produção e seu consumo. 


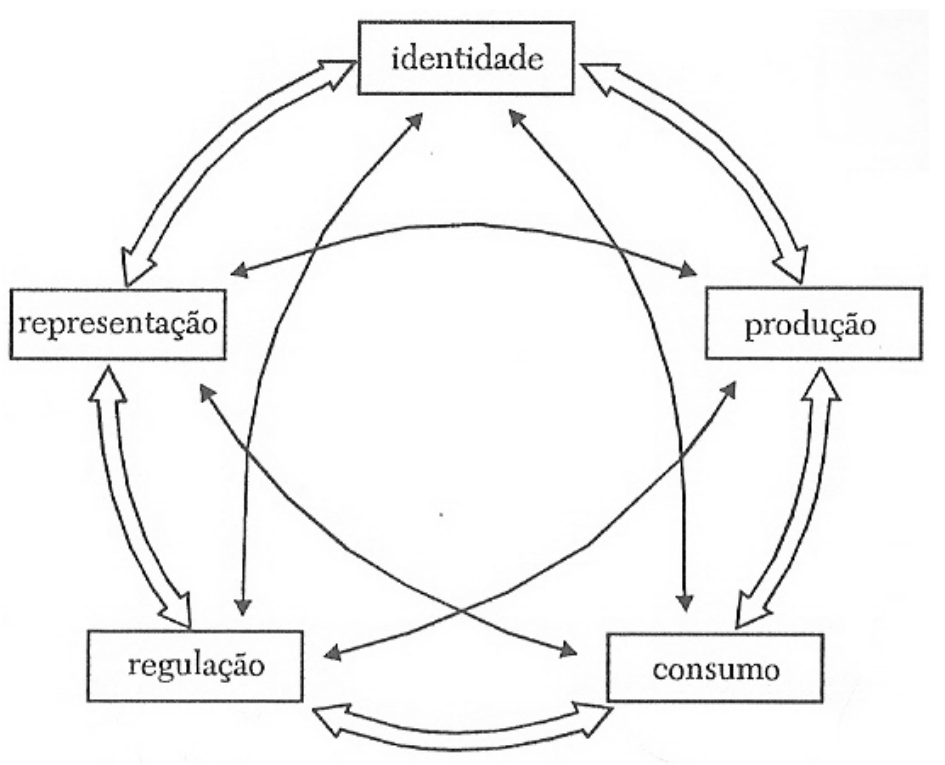

Figura 1: Circuito da cultura, segundo du Gay et al (1997).

\subsection{Identidade e representação}

Para analisarmos os sistemas simbólicos de representação, precisamos pensar a relação entre cultura e significado. As representações são constituídas através de práticas de significação e de sistemas simbólicos que produzem significados e nos posicionam como sujeitos. São esses significados culturais que dão sentido às nossas experiências e àquilo que somos, tornando possível ser o que somos, ou no que podemos nos tornar (HALL, 1996).

O discurso, como constitutivo e disseminador de sistemas simbólicos, é fundamental para o processo de formação de identidades. Podemos tomar como exemplo a mídia, criadora e disseminadora de inúmeros sistemas simbólicos e produtora de discursos que nos ensinam como ocupar posições de sujeito e quais dessas posições são socialmente privilegiadas. 


\subsection{Identidade e diferença}

A marcação da diferença é um elemento central na formação de posições de identidade. Segundo a antropóloga Mary Douglas (1966), a marcação da diferença é a base da cultura ${ }^{7}$ porque é através dela que pessoas e coisas são classificadas e posicionadas socialmente, ganhando, assim, sentido.

A diferença, como aquilo que separa uma identidade da outra, é central para a formação das identidades. A marcação da diferença é também central para o estabelecimento dos sistemas classificatórios dos quais as identidades tanto dependem. Um sistema classificatório, como um princípio estruturante dos sistemas simbólicos e da ordem social, "aplica um princípio de diferença a uma população de uma forma tal que seja capaz de dividi-la (e a todas as suas características) em ao menos dois grupos opostos - nós/eles [...]; eu/outro" (WOODWARD, 2000, p. 40).

Assim, os sistemas classificatórios culturais são calcados na diferença entre categorias, diferenças que são estruturadas sobre oposições binárias (dentro/fora, acima/abaixo, homem/mulher, insiders/outsiders). O controle social é obtido, em parte, pela produção de categorias que posicionam aqueles que transgridem as normas sociais como 'outsiders'. Podemos afirmar, portanto, que "a classificação simbólica está $[$... intimamente relacionada à ordem social” (WOODWARD, 2000, p. 46).

Como argumentei até aqui, as oposições binárias - a forma mais extrema de marcar a diferença - são determinantes na construção dos significados (SAUSSURE, 1978; HALL, 1996). Na linha das análises estruturalistas baseadas em Saussure, o contraste (ou a diferença) é um princípio da estrutura lingüística. Como corolário da centralidade das oposições binárias para a produção dos significados e da linguagem, os sistemas de pensamento (numa veia lingüística crítica, os discursos) são estruturados a partir de dualismos que constroem a diferença como oposições cristalinas - natureza/cultura, corpo/mente, razão/emoção (WOODWARD, 2000). As dicotomias são, na verdade, uma das formas através

\footnotetext{
${ }^{7}$ A ordem social é, em parte, resultado da aplicação de sistemas classificatórios à vida social. Nessa linha, podemos definir cultura como um conjunto de sistemas classificatórios compartilhados entre os membros de uma sociedade que lhes permite dar sentido ao mundo social e produzir significados (WOODWARD, 2000).
} 
das quais a cultura tenta fixar os significados e negar seu caráter absolutamente contingente.

\subsection{Discurso e identidades de gênero}

O interesse pelas questões de gênero surgiu com mais vigor a partir dos anos 1960, com o advento dos movimentos feministas. Atualmente, a investigação sobre as questões relativas ao gênero tornou-se uma área de sólida pesquisa e teorização em várias universidades em todo mundo, em campos diversos como a sociologia, a psicologia, a antropologia, os estudos literários e os estudos lingüísticos. Como afirmam Cranny-Francis et al, "gênero é uma das principais categorias feministas de análise, categoria que está em intersecção com muitos outros sistemas sociais (raça, sexualidade) que também são governados por oposições binárias" (2003, p. 4).

O gênero é um sistema binário que divide os seres humanos em duas categorias: homens e mulheres. Sua força conceitual e material é tamanha que esse sistema organiza virtualmente todos os aspectos de nossas vidas, desde os mais íntimos até os mais públicos. Como afirmam Cranny-Francis et al, "todos os corpos humanos nas sociedades modernas são alocados um lugar na estrutura binária de gênero" (2003, p. 1). Entretanto, como lembram as autoras, o sistema de gêneros é insidioso e naturalizado, e está presente em todos os espaços sociais, o que muitas vezes faz com que seja difícil detectar seu funcionamento.

Entre os dois termos de um par binário (e.g. homem/mulher) existe um desequilíbrio necessário de poder (DERRIDA, 1976). Para as críticas feministas, no caso do gênero, esse desequilíbrio sempre privilegia o termo masculino do par, atribuindo ao termo feminino uma posição secundária. Essa oposição de poder é também a base das divisões sociais, especialmente as existentes entre homens e mulheres (cf. CIXOUS, 1975). É por meio de "dualismos que as mulheres são construídas como 'outras', de forma que as mulheres são apenas aquilo que os homens não são, como ocorre na teoria psicanalítica lacaniana" (WOODWARD, 2000, p. 52).

Em síntese, o sistema de gênero não só divide a raça humana em duas categorias, mas privilegia a categoria masculina em relação à feminina. Nesse sentido, o gênero, como um dos sistemas classificatórios formadores 
da cultura, funciona como uma forma de estruturar hierarquicamente os papéis sociais.

Do ponto de vista dos estudos feministas, o conceito de gênero é geralmente definido em relação ao conceito de sexo: o gênero seria a construção cultural ou social do sexo. Do ponto de vista antropológico ou sociológico, o conceito de gênero não se refere somente à que gênero pertencemos (homem ou mulher), mas a um conjunto de significados que nosso sexo assume em cada sociedade. Esses significados são organizados socialmente como "masculinidade" e "feminilidade" e combinados com corpos masculinos e corpos femininos. Para algumas teóricas, entretanto, "não há corpo, não há sexo biológico, fora do gênero: [...] ao nos tornamos humanos, já somos automaticamente estruturados como um gênero" (CRANNY-FRANCIS et al, 2003, p. 3).

Connell (1995) também propõe um modelo de gênero que se afasta das ideologias biológicas. Para este autor, feminilidade e masculinidade coexistem em cada indivíduo, dependendo e variando de acordo com os distintos contextos sociais e, portanto, deveriam ser vistos como dimensões separadas, e não pólos naturais opostos, das identidades sociais e individuais. Nessa perspectiva, as identidades de gênero são impactadas por normas e avaliações sociais, por estruturas de poder e pelos processos de socialização.

Judith Butler (1990) apresenta outra explicação, compartilhada por muitas pesquisadoras, para o funcionamento social do gênero. Segundo essa autora, o gênero é um processo de incorporação (embodiment) gerado pelo desempenho repetitivo de atos de gênero. De forma similar a Foucault, Butler atribui um poder normativo à própria noção de identidade de gênero e à tentativa de descrevê-la. Alinhando-se com a posição de Butler, Wodak (1997) afirma que a simples definição de gênero exclui e desvaloriza muitos corpos, práticas e discursos, ao mesmo tempo em que esconde seu caráter social e culturalmente construído e sua aura de retidão.

Nessa linha, fala-se atualmente em 'fazer um gênero' e não mais em 'ter um gênero'. A expressão 'fazer gênero' indica que o pertencimento a um gênero não está ligado ao conjunto de atributos de cada sujeito, mas sim ao que esse sujeito 'faz'. Em outras palavras, pertencer a um gênero constitui um ato performativo e não um fato, uma vez que os gêneros são realizados de forma contínua nas interações sociais. Os gêneros resultam não só das atividades diárias que caracterizam o 'fazer um gênero', mas 
também da assimetria nas relações entre os sexos, da dominação do 'masculino' e de seu caráter de norma.

Segundo Hall (1996, p. 11), o corpo sutura, numa mesma localização espacial/temporal, as muitas possibilidades subjetivas abertas para os sujeitos contemporâneos. Como argumenta Woodward, "o corpo é um dos locais envolvidos no estabelecimento das fronteiras que definem quem nós somos, servindo de fundamento para a identidade" (2000, p. 15).

A construção identitária, incluindo a construção do corpo, se torna possível através das narrativas e representações que caracterizam cada sociedade, com base nas quais os sujeitos constroem narrativas individuais minimamente coerentes. E podemos afirmar que é através dos textos que circulam em suas comunidades que os sujeitos sociais se familiarizam com os modelos narrativos e representacionais presentes na cultura e constroem suas identidades através de representações. Do ponto de vista dos estudos de gênero e dos estudos identitários, os textos, e as representações culturais que eles constroem, são espaços privilegiados para explorar as possibilidades abertas para os indivíduos em sua constituição como sujeitos de gênero.

Os estudos feministas, em todas as áreas acadêmicas, são caracterizados pela crítica às visões androcêntricas presentes nas 'ciências tradicionais'. A lingüística feminista adota a mesma posição crítica, e muitas de suas propostas e pressupostos básicos se relacionam e se sobrepõem com princípios da $\mathrm{ACD}$, assim como com o paradigma qualitativo das ciências sociais (WODAK, 1997).

As pesquisas nessa área têm indicado que, embora formas explícitas de discriminação contra as mulheres estejam desaparecendo, desigualdades de gênero perduram na cultura e se fazem sentir, ainda que de forma mais velada, nas relações e práticas sociais. $\mathrm{O}$ discurso e a linguagem, que mediam e ajudam a construir essas relações e práticas sociais, continua marcado por normas androcêntricas (HEBERLE, 2000).

\section{Análise Crítica do Discurso: abordagem transdisciplinar para estudos críticos da linguagem}

Segundo Ramalho, a ACD constitui "uma abordagem científica transdisciplinar para estudos críticos da linguagem como prática social” (2008, 
p. 44). Essa abordagem está inserida na tradição das "ciências sociais críticas", que desenvolvem pesquisas que possam oferecer suporte científico a questões sociais relacionadas ao poder, à descriminação, à exclusão social, à justiça, à cidadania, etc. Como abordagem transdisciplinar, a ACD rompe fronteiras epistemológicas com diversas áreas das ciências sociais, valendose de teorias delas provindas para apoiar sua abordagem sociodiscursiva, ao mesmo tempo em que oferece as/aos cientistas sociais a possibilidade de acrescentar um viés discursivo a suas investigações.

Como ciência crítica, o foco da ACD são os efeitos ideológicos que os eventos discursivos (ou textos, num sentido amplo) exercem sobre nossas formas de nos relacionarmos e agirmos socialmente, nossas formas de ser (ou nossas identidades), e nossos sistemas de valores, crenças e atitudes. Na perspectiva crítica de Thompson (2002), a ACD investiga como o discurso, e os sentidos textuais, atuam "a serviço de projetos particulares de dominação e exploração, que sustentam a distribuição desigual de poder [na sociedade]" (RAMALHO, 2008, p. 45).

Uma das premissas básicas da ACD é que texto e discurso não podem ser dissociados das práticas sociais. Chouliaraki e Fairclough (1999) argumentam que nem toda interação social tem um caráter discursivo, mas a maior parte das interações depende substancialmente do discurso, justificando focalizá-lo como forma de interpretar as interações sociais. Toda prática social é tanto produtiva quanto reflexiva, isto é, toda prática inclui pessoas envolvidas em relações sociais aplicando tecnologias a materiais, mas também inclui representações dessa prática como parte integrante da própria prática. $\mathrm{O}$ discurso participa das práticas sociais de duas formas: as práticas são parcialmente discursivas (na medida em que falar, escrever, ler e ouvir são formas de ação), mas também são discursivamente representadas. Se essas representações auxiliarem a manutenção de relações de dominação dentro das práticas, elas podem ser chamadas de ideológicas.

O foco atual da ACD é a análise das relações dialéticas entre a semiose (incluindo a linguagem) e outros elementos das práticas sociais. Mais especificamente, os trabalhos dentro dessa abordagem se centram nas mudanças radicais que têm ocorrido na vida social contemporânea, no papel da semiose em processos de mudança, e nas mudanças na relação existente entre a semiose e outros elementos não-semióticos das redes de práticas sociais. Segundo Fairclough (2003b), o papel da semiose nas práticas sociais não pode ser tomado como dado, mas precisa ser estabelecido através da análise. 


\section{LSF: Base lingüística para a teoria social do discurso}

A ACD está baseada na noção de que o uso da linguagem, ou discurso, é um modo de ação social e historicamente situado, numa relação dialética com outros aspectos do social - ou seja, ele é formado socialmente, mas também forma o social. Para a teria social do discurso, o uso da linguagem simultaneamente constitui (i) identidades sociais, (ii) relações sociais, e (iii) sistemas de conhecimento e crença (FAIRCLOUGH, 1992).

Esses três aspectos constitutivos do discurso estão ligados a Lingüística Sistêmica Funcional (LSF), a teoria lingüística de base para a ACD. Segundo Fairclough, a lingüística sistêmica funcional (LSF) é bastante adequada para a ACD por estar "profundamente interessada na relação entre linguagem e outros elementos e aspectos da vida social, e [por] sua abordagem à análise lingüística de textos [ser] sempre orientada para o caráter social dos textos" (FAIRCLOUGH, 2003, p. 5).

Por conceber a linguagem como um sistema sócio-semiótico, a LSF vem servindo de teoria lingüística básica para na área da $A C D$ desde seu surgimento, quando ainda era chamada de Lingüística Crítica (FOWLER et al, 1979), assim como para os trabalhos mais recentes de Fairclough (2003, 2006) e de Kress e van Leeuwen (1996, 2001), oferecendo ferramentas que permitem a análise léxico-gramatical dos usos da linguagem em contextos específicos. Sobre a ligação entre a ACD e a LSF, Magalhães (2005) afirma que a ACD:

Estabelece ligação com dois fortes campos de estudos: de um lado, a teoria social crítica e, de outro, a lingüística sistêmico-funcional. [...] A definição de linguagem em que ambas se baseiam é a de lingüística instrumental: o estudo da linguagem para compreender outros fenômenos, apresentando carac-terísticas que dependem do propósito do estudo. [...] A lingüística sistêmico-funcional defende a idéia de que os sistemas lingüísticos são abertos à vida social, pois se constroem na interseção das macrofunções da linguagem: ideacional; interpessoal; e textual. Essa abordagem da linguagem é fundamental para o desenvolvi-mento da teoria crítica do discurso.

Todas as teorias lingüísticas funcionais enfatizam o caráter multifuncional dos textos. Segundo a LSF (HALLIDAY, 2004), os textos realizam, simultaneamente, três funções: a ideacional (através dos textos representamos aspectos do mundo, de modo histórico, social e culturalmente situado); a interpessoal (os textos desempenham relações sociais entre os 
participantes de um evento social, assim como as atitudes, crenças a valores desses participantes); e a textual (a linguagem, e os textos, nos permitem construir mensagens coesas e coerentes, ligadas aos seus contextos situacionais, capazes de serem compreendidas pelos participantes do evento discursivo).

Assim como Halliday vê a linguagem como multifuncional, Fairclough também vê os textos como multifuncionais, embora de forma distintai.e., segundo esse último autor os textos refletem e constroem formas de representar, formas de agir e formas de ser, estando ligados ao evento social no qual são gerados, aos participantes desse evento, e ao mundo físico e social mais amplo. Nessa perspectiva, Fairclough prefere falar não em funções exercidas pelos textos, mas em diferentes significados que eles criam, reproduzem ou alteram. Segundo o autor, os três grandes grupos de significados textuais são:

- Representacionais: correspondem à metafunção ideacional de Halliday.

- Acionais: correspondem à metafunção interpessoal de Halliday. Ao investigarmos os significados acionais de um texto nosso foco está na forma como esse texto atua como meio de interação em eventos sociais, englobando as relações entre os participantes (i.e. os textos desempenham relações sociais).

- Identitários: também correspondem à função interpessoal de Halliday, embora Halliday não distinga entre as funções relacionais e identitárias da linguagem. Para Fairclough, por outro lado, o que Halliday chama de função interpessoal é dividida em dois grupos de significados: os acionais, relativos às relações sociais estabelecidas via texto, e os identitários, relativos às formas de ser, às identidades sociais construídas pelos textos. ${ }^{8}$

Esses três grupos de significados estão presentes simultaneamente em qualquer texto. A divisão apresentada acima tem apenas fins organizacionais. Cruzando a visão do discurso como constitutivo da sociedade, os três

\footnotetext{
${ }^{8}$ Quanto à terceira metafunção hallidayana, a textual, Fairclough não distingue um grupo de significados textuais separadamente, mas os inclui dentro dos significados acionais (2003).
} 
grupos de significados textuais identificados por Fairclough e as metafunções textuais propostas por Halliday, teríamos o seguinte:

\begin{tabular}{|c|c|c|}
\hline $\begin{array}{lcc}\text { Aspectos } & \text { do } & \text { social } \\
\text { constituídos } & \text { (em } & \text { parte) } \\
\text { pelo discurso } & & \end{array}$ & $\begin{array}{l}\text { Significados textuais } \\
\text { (Fairclough, 2003a) }\end{array}$ & $\begin{array}{l}\text { Metafunções hallidayanas } \\
\text { (Halliday, 2004) }\end{array}$ \\
\hline $\begin{array}{l}\text { Sistemas de conhecimento e } \\
\text { crença }\end{array}$ & Representacionais & Metafunção ideacional \\
\hline Relações sociais & Acionais & Metafunção interpessoal \\
\hline Identidades sociais & Identitários & Metafunção interpessoal \\
\hline
\end{tabular}

Quadro 1: Cruzamento da visão social da linguagem segundo a ACD e a LSF.

\section{Linguagem e gênero nas perspectivas da ACD e da LSF}

Para investigar como os textos, através de significados representacionais, acionais e identitários, representam, constroem e/ou alteram o social, para essa apresentação selecionei duas matérias sobre emagrecimento publicadas nas revistas Corpo a Corpo ("Como você se relaciona com a comida?", Julho 2004) e Boa Forma ("Dieta das 7 chaves: tranque o efeito sanfona para fora de sua vida", Julho 2004), ilustradas visualmente abaixo. Esse trabalho pertence ao projeto "A representação das transformações corporais e identitárias pós-modernas nos discursos midiáticos", que venho desenvolvendo no Programa de Pós-Graduação em Ciências da Linguagem da Unisul desde 2005, em parceria com alunos do mestrado (SILVA, 2007; MELLO, 2008; DAUFEMBACK, 2008; PRATTS, 2009; FIGUEIREDO, 2009; 2008a, b, c; 2005). O projeto tem como objetivo investigar, com base nos construtos teóricos e metodológicos da Análise Crítica do Discurso, da Lingüística Sistêmica Funcional, dos Estudos de Gênero, e dos Estudos Culturais, como a mídia representa as transformações que o corpo feminino tem sofrido a partir do final do século XX, e como as identidades femininas tem sido alteradas por essas transformações. 


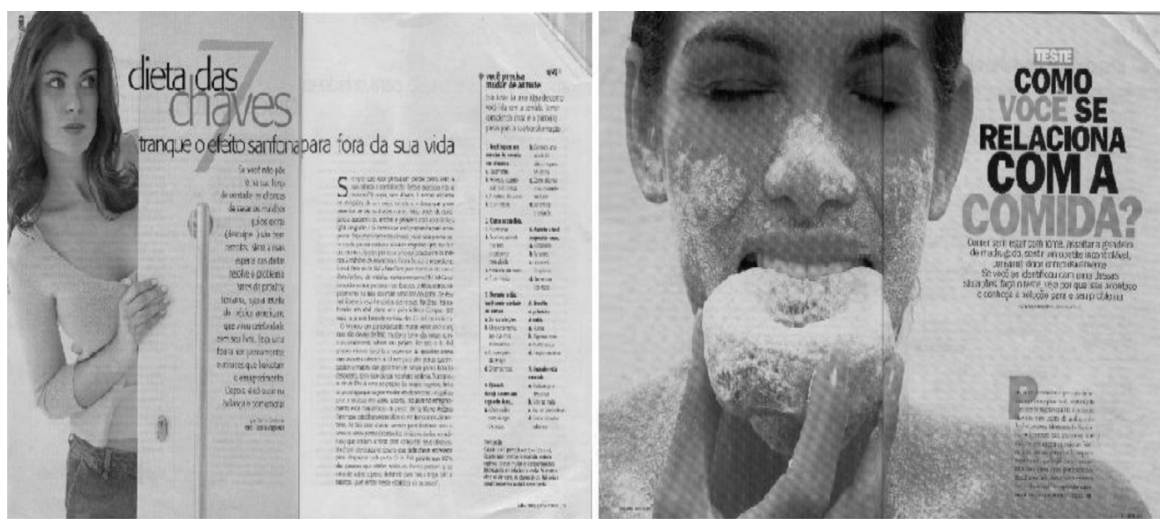

Figura 1: Matérias analisadas.

Em termos identitários (ou interpessoais, na terminologia hallidayana), os textos analisados apresentam inúmeros exemplos do papel da mídia na construção reflexiva da identidade da consumidora textual. A leitora é retratada como alguém que, embora saiba do imperativo do corpo magro, não consegue alcançá-lo sozinha devido a 'problemas' de ordem emocional:

- Se você não põe fé na sua força de vontade, as chances de secar os malditos quilos extras (desculpe ...) são bem remotas. Nem a mais esperta das dietas resolve o problema. (A dieta das 7 chaves)

- Seja absolutamente sincera: você está pronta para mudar pensamentos e atitudes negativas que, no fundo, são culpados por essa silhueta pesada? (A dieta das 7 chaves)

O campo semântico criado pelas palavras e expressões destacadas acima (não ter força de vontade; pensamentos e atitudes negativas) retrata a leitora como alguém incapaz de exercer o controle e a disciplina corporais que nos tornam agentes sociais respeitados e respeitáveis.

Para investigar os tipos de significados acionais (ou interpessoais, na terminologia hallidayana) construídos por esses textos, explorei, em termos léxico-gramaticais, o tipo de relação estabelecida entre a revista e suas leitoras. Através da mediação cultural, é construída uma relação de poder na qual a revista ocupa o papel de possuidora, ou ao menos tradutora, de conhecimentos científicos e técnicos, cabendo à leitora o papel de leiga que 
busca na revista a solução de certos problemas (no caso em questão, a falta de controle corporal). Nas perspectivas da ACD e da LSF, a relação entre os participantes de um evento discursivo é construída através dos significados acionais, ou da metafunção interpessoal, respectivamente. Segundo Fairclough, os significados acionais estão ligados, em nível oracional, aos tipos de trocas que fazemos através de uma oração. Basicamente, há dois tipos de troca: as trocas de conhecimento, que envolvem dar e receber informação, fazer asserções, declarar fatos, etc.; e as trocas de atividade, que envolvem uma atividade na qual os participantes fazem coisas ou levam outras pessoas a fazerem coisas (2003, p. 105). Essa distinção está ligada a alguns atos de fala básicos, como as declarações (trocas de conbecimento), as perguntas, as demandas e as ofertas (trocas de atividade). Os significados acionais são construídos também através dos modos oracionais, ou seja, são realizados através de oraçoes declarativas, interrogativas e imperativas.

Para melhor entender e explicar as diferenças entre trocas de conhecimento e trocas de atividade, Fairclough faz uso da distinção proposta por Habermas (1984) entre ações comunicativas e ações estratégicas. As ações comunicativas ocorrem em interações cujo objetivo é chegar a um entendimento (e.g. uma conversa pessoal com um amigo), enquanto que as ações estratégicas ocorrem em interações cujo objetivo é obter resultados (e.g. uma transação de compra e venda). Ao utilizar essa distinção, entretanto, temos que levar em conta que, muito frequentemente, os textos realizam ações estratégicas (e.g. procuram influenciar, dirigir ou modificar o comportamento dos/as receptores/as) mascaradas como trocas de conhecimento, ou ações comunicativas (FAIRCLOUGH, 2003).

Isso é o que ocorre nos dois textos analisados nesse artigo. As matérias sobre emagrecimento se pretendem, a princípio, informativas, ou seja, apresentam-se como trocas de conhecimento ou ações comunicativas entre a revista e suas leitoras, informando essas últimas sobre como ter sucesso em uma dieta. Entretanto, essas matérias, em nível de atos de fala, apresentam orações que envolvem não só dar e receber informações e declarar fatos (trocas de conbecimento, ou ações comunicativas), mas também fazer afirmações, perguntas, demandas e ofertas (trocas de atividade, ou atos estratégicos). Em outras palavras, o caráter inicialmente informativo das matérias não exclui a presença de um outro caráter, de ordem instrumental, que se materializa na estrutura dos atos de fala e nos modos oracionais, estabelecendo relações assimétricas de poder (às vezes abertas, outras vezes mitiga- 
das) entre revista e leitora. A revista prescreve e proscreve comportamentos alimentares para as leitoras, e essa relação de prescrição/proscrição é marcada tanto em nível lexical quanto em nível gramatical: ora os textos recorrem a sugestões e conselhos modalizados, ora a ordens claras (demandas) dadas no modo imperativo:

\section{Demandas abertas (imperativos)}

- Faça o teste

- Conbeça a solução para o seu problema

- Procure fracionar as refeições

(Como você se relaciona com a comida?)

- Siga a receita do médico americano

- Faça uma faxina nos pensamentos e atitudes

- Expulse os pensamentos derrotistas

(A dieta das 7 chaves)

\section{Demandas modalizadas}

- Para quebrar esse ciclo vicioso, a recomendação é abrir a porta do controle emocional.

- Nem sempre é possível mudar os acontecimentos, mas você pode transformar o jeito de interpretá-los.

- Pode ser uma volta no quarteirão, desde que faça isso todos os dias. (A dieta das 7 chaves).

- Substituir o vício de comer a todo momento pela prática de um esporte pode ser uma escolba acertada.

- Não é preciso abrir mão do sabor e da qualidade.

- Preparar receitas light é um bom recurso. Outra dica é se entregar às delícias com mais calorias somente nos fins de semana.

- Também é bom evitar fast-foods italianos.

(Como você se relaciona com a comida?)

Outra evidência da natureza estratégica das trocas presentes nas matérias analisadas é a presença de ofertas (e.g. promessas de resultados positivos) e perguntas, ambas atos de fala que representam trocas de atividade. Vejamos alguns exemplos:

\section{Perguntas}

- [...] Você está pronta para mudar pensamentos e atitudes negativas que, no fundo, são os culpados por essa silhueta pesada? (A dieta das 7 chaves). 
- Quando você está triste, como de forma descontrolada elou aleatória? (Como você se relaciona com a comida?)

- Alterna fases em que come menos com períodos em que consome demais? (Como você se relaciona com a comida?)

\section{Ofertas (promessas de resultados positivos)}

- [...] Em vez de se convencer que você é um caso sem solução, acredite de verdade que vai conseguir se controlar diante da comida e será uma vencedora. Quando chegar nesse estágio, vai estar de posse da preciosa chave do autocontrole. (A dieta das 7 chaves)

- Outro conselbo: acostume seu paladar a hortaliças e frutas. Pronto, você abriu a porta do controle da comida. (A dieta das 7 chaves)

Como podemos ver, através da combinação de demandas abertas (modo imperativo) com demandas mitigadas (modo declarativo modalizado), de declarações informativas (trocas de conhecimento) com perguntas e ofertas (trocas de atividade), o discurso das revistas femininas procura mascarar as relações de poder entre a instituição e suas leitoras. Textos de atividade (que realizam atos estratégicos) mascarados como textos de conhecimento (que realizam atos comunicativos) são comuns nas revistas femininas. Como manuais de feminilidade e veiculadoras de um discurso eminentemente promocional, as revistas femininas procuram influenciar e moldar o comportamento de suas leitoras - principalmente no que diz respeito a convencê-las a consumir os produtos e serviços promovidos pelas matérias (no caso desse artigo, dietas, produtos dietéticos, serviços de profissionais liberais como médicos, terapeutas, nutricionistas, etc.). Entretanto, essas trocas estratégicas são apresentadas como trocas comunicativas, mitigando a verticalidade das relações de poder entre produtoras e consumidoras textuais, e a distância social entre elas.

Por fim, para investigar os tipos de significados representacionais (ou ideacionais, na terminologia hallidayana), podemos, por exemplo, analisar, em nível micro-textual, os grupos lexicais (i.e. os grupos de significados) que predominam nesses textos, e que visões de mundo esses significados constroem.

Em termos de representações de mundo, os dois textos estão estruturados sobre o ideal hegemônico de beleza magra. Eles reconstroem a tradicional dicotomia 'gordo x magro', premiando o corpo magro e atribuindo 
um valor negativo à gordura, através do uso de epítetos e qualificadores localizados em locuções nominais ou orações adjetivas. Os epítetos classificam as 'coisas' mencionadas nos textos (na análise em questão, o corpo da leitora) através de adjetivos (e.g. enxuto, sonhadas, pesada), enquanto que os qualificadores especificam a categoria à qual a coisa mencionada pertence, seja através de adjetivos (e.g. um corpo enxuto) ou substantivos (e.g. o desprazer da gula) (HALLIDAY, 2004). Vejamos alguns exemplos:

- A dupla (dieta e exercício) sem dúvida é a mais eficiente na conquista de um corpo enxuto e a única que pode desenhar as tão sonbadas curvas. (Como você se relaciona com a comida?).

- Você quer um corpo magro, mas seus pensamentos negativos boicotam seu objetivo. (Como você se relaciona com a comida?).

- Um bom exercício (...) é se perguntar: como meu peso tem interferido na minha autoestima? Quais as recompensas de estar gordinha? As respostas, com certeza, não serão positivas e podem ajudar você a refletir melhor sobre o desprazer da gula. (A dieta das 7 chaves).

A gordura, ou excesso de peso, é associada à forma como a leitora lida com a comida. Nessa linha, o controle alimentar é descrito como um traço altamente positivo e desejável, e a ingestão 'descontrolada' de alimentos como um problema a ser eliminado a todo custo:

- No entanto, é introvertida, fazendo com que sua válvula de escape seja a comida. Resultado: um fast-food é sempre bem vindo. Esse é seu pecado: se entregar às praticidades. (Como você se relaciona com a comida?)

A solução, segundo os textos, é a disciplina. Esse é um tema recorrente em ambas as matérias. A importância do controle corporal fica clara nas opções lexicais de "A dieta das 7 chaves":

- Controle sobre o peso

- Autocontrole

- Preciosa chave do autocontrole

- Controle emocional

- Controle externo

- Controle dos hábitos

- Controle da comida

- Controle do corpo

- Controle social 
Já no texto "Como você se relaciona com a comida" surge o campo semântico do descontrole e da indisciplina alimentar, que leva à patologia, à perda do valor social e à construção de uma identidade problemática, como indicam os grupos nominais e os itens lexicais abaixo:

- Compulsão

- Crise

- Válvula de escape

- Alívio imediato para suas crises

- Vício de comer

- Compulsão alimentar

- Beliscar

- Costumes errados

- Ingestão constante de frituras

- Exagerar

- Tentação

- Excesso

- Ponto fraco

- Intensas e ansiosas

O léxico ocupa um duplo papel em um texto: a um só tempo demonstra e constrói a forma como vemos a realidade. Através de nossas escolhas lexicais revelamos nossos valores e crenças, assim como nosso posicionamento ideológico, político e social (FAIRCLOUGH, 1989; HEBERLE, 1997). Em resumo, as duas matérias aqui analisadas desempenham um forte papel pedagógico de controle corporal, premiando quem é capaz de internalizar as técnicas de autodisciplina (por exemplo, através de escolhas lexicais como transformação, virada, evolução, sucesso, comemorar), e apontando os riscos sociais e subjetivos para aquelas que se deixarem levar pelos 'prazeres' da mesa (diabetes, colesterol e obesidade; compulsão; vício; exagero; silhueta pesada; atrapalhar sua vida social).

\section{Comentários finais}

Quanto à relação entre linguagem e gênero social, como as pesquisas nessa área focalizam o modo como a linguagem intermedeia, mantém ou muda práticas e identidades sociais, tanto a ACD quanto a LSF constituem 
suportes teóricos e metodológicos bastante apropriados para investigar, por exemplo, através de textos midiáticos sobre o corpo, o aspecto semiótico das práticas sociais voltadas para a disciplina e o controle do corpo na modernidade tardia, assim como as estruturas sociais mais amplas que definem o potencial de significados que podem ser construído em eventos sociais específicos (ou, numa veia lingüística, nos textos) que constituem e representam o corpo e as identidades de gênero na modernidade tardia.

E-mail: deborafigueiredo@terra.com.br

\section{REFERÊNCIAS}

Bourdieu, P. Distinction: a social critique of the judgment of taste. Cambridge, MA: Harvard UP, 1984.

Butler, Judith. Problemas de gênero - Feminismo e subversão da identidade. Rio de Janeiro: Civilização Brasileira, [1990] 2003.

CAMERON, D. Verbal Hygiene . London : Routledge, 1995.

Feminism and Linguistic Theory. London : Macmillan, 1992.

The feminist critique of language: A reader. $2^{\text {nd }} \mathrm{Ed}$. London: Routledge, 2002.

Cixous, H. Sorties, La Jeune Née. In: Marks, E; de Courtivron (Eds.) New

French feminisms: An anthology. Amherst, MA: The University of Massachusetts Press, [1975]1980.

Chouliaraki, L.; Fairclough, N. Discourse in late modernity. Edinburgh: Edinburgh UP, 1999.

Connell, R. W. Masculinities: Knowledge, power and social change. Berkeley/Los Angeles: University of California Press, 1995.

Cranny-Francis, A. et al (Eds.) Gender studies: Terms and debates. London: Palgrave/Macmillan, 2003.

Daufemback, A.A. O imperativo do corpo magro e identidades corporais adolescentes na revista Capricho: uma análise a partir da gramática visual. Dissertação (Mestrado em Ciências da Linguagem) - Universidade do Sul de Santa Catarina, 2008. Disponível em: http:/ /www3.unisul.br/paginas/ensino/pos/linguagem/disserta/index.htm.

Derrida, J. On grammatology. Baltimore/London: MD/Johns Hopkins UP, 1976.

Douglas, M. Purity and danger: An analysis of pollution and taboo. London: Routledge, 1966. 
Du GaY, P. et al (Eds) Production of culture/Cultures of production. London: Sage/The Open University, 1997.

Durkheim, E. The elementary forms of the religious life. London: Allen \& Unwin, 1954.

ECKert, P.; McConnell-Ginet, S. Language and gender. Cambridge: Cambridge University, 2003.

FAirclough, N. Language and power. London: Longman,1989. . Discourse and social change. Cambridge: Polity Press,1992. A análise crítica do discurso e a mercantilização do discurso público: as universidades. In: C. MAGALHÃES (Org.) Reflexões sobre a análise crítica do discurso. Belo Horizonte: FALE-UFMG, 2001.

Analysing discourse: Textual analysis for social research. London: Routledge, 2003a.

. El análisis crítico del discurso como método para la investigación en ciencias sociales. In: WodAK, R.; Meyer, M. Métodos de análisis crítico del discurso. Barcelona: Gedisa Editorial, p. 179-204, 2003b. . Language and globalization. London: Routledge, 2006.

FigueIREDO, D.C. Narrative and identity formation: an analysis of media personal accounts from patients of cosmetic plastic surgery. In: Bazermann, C.; Bonini, A.; Figueiredo, D.C. (Eds.) Genre in a changing world: Advances in genre theory, analysis, and teaching. West Lafayette, IN: Parlor Press; Fort Collins, CO: WAC Clearinghouse, 2009.

. "Como você se relaciona com a comida?" A construção da identidade feminina no discurso midiático sobre o emagrecimento. Matraga, vol. 15, jan/jun, 2008a.

. Discurso, corpo e identidade: a construção de identidades femininas nas revistas Boa Forma e Corpo a Corpo. In: MotTa-Roth, D.; Cabanas, T.; Hendges, G.R. (Orgs.) Práticas de análise do texto e do discurso. Santa Maria, RS: DLEM/PPGL - UFSM, 2008b.

. Mídia, design corporal e identidade na pós-modernidade: os discursos sobre o emagrecimento e a cirurgia plástica cosmética. In: Matzenauer, C.L.B; Miranda, A.R.M.; Finger, I; Amaral, L.I.C. (Orgs.) Estudos da Linguagem - VII Círculo de Estudos Lingüísticos do Sul. Pelotas: EDUCAT/UCPel-Pelotas, 2008c.

. Culto ao corpo e identidade feminina: uma análise do discurso midiático sobre o emagrecimento. Atas do I Simpósio Internacional de Análise do Discurso Crítica. Brasília: Editora da UnB, 2005. 
FowLER, R. et al (Eds) Language and control. London: Routledge \& Kegan Paul, 1979.

Habermas, J. Theory of communicative action, Vol. 1. London: Heinemann, 1984.

Hall, S. Who needs identity? In: HaLl, S; Du GaY, P. (Eds.) Questions of identity. London: Sage, 1996.

Halliday, M.A.K. An introduction to functional grammar. $3^{\text {rd }}$ ed. London: Edward Arnold., 2004.

Heberle, V.M. Critical Reading: Integrating Principles of Critical Discourse Analysis and Gender Studies. Ilha do Desterro, v. 38, 2000.

An investigation of textual and contextual parameters in editorials of women's magazines. Unpublished Doctoral dissertation. Florianópolis: Universidade Federal de Santa Catarina, 1997.

Heberle, V.M.; Ostermann, A.C.; Figueiredo, D.C. Linguagem e gênero no trabalho, na mídia e em outros contextos. Florianópolis: Editora da UFSC, 2006.

Holmes, J.; Meyerhoff, M. The handbook of language and gender. Malden, MA: Blackwell, 2005.

Kress, G.; Van Leeuwen, T. Reading images: the Grammar of Visual Design. London: Routledge, 1996.

Multimodal Discourse: the modes and media of contemporary communication. London: Arnold, 2001.

Mello, F.C. A representação de identidades corporais femininas pósmodernas na mídia de massa: Os discursos das revistas de moda. Dissertação (Mestrado em Ciências da Linguagem) - Universidade do Sul de Santa Catarina, 2008. Disponível em: http://www3.unisul.br/ paginas/ensino/pos/linguagem/disserta/index.htm

PratTs, S.M. Interação entre leitora adolescente e a temática do corpo na revista Capricho: Uma perspectiva discursiva crítica. (Mestrado em Ciências da Linguagem) - Universidade do Sul de Santa Catarina, 2009. Disponível em: http://www3.unisul.br/paginas/ensino/pos/ linguagem/disserta/index.htm

Ramalho, V.C.V.S. Discurso e ideologia na propaganda de medicamentos: Um estudo crítico sobre mudanças sociais e discursivas. Tese (Doutorado em Lingüística) - Universidade de Brasília (UnB), 2008.

SAussure, F de. Course in general linguistics. London: Collins, 1978. 
SILVA, F. "Eu consegui!”: A representação de identidades corporais contemporâneas no discurso midiático sobre o emagrecimento. Dissertação (Mestrado em Ciências da Linguagem) - Universidade do Sul de Santa Catarina, 2007. Disponível em: http://www3.unisul.br/ paginas/ensino/pos/linguagem/disserta/index.htm.

Thompson, J. B. A mídia e a modernidade: uma teoria social da mídia. $4^{\mathrm{a}}$. ed. Petrópolis: Vozes, 2002.

WoDAK, R (Ed). Gender and discourse. London: Sage, 1997.

WoODWARD, K. Identidade e diferença: uma introdução teórica e conceitual. In: SILVA, T.T. (Org.) Identidade e diferença: a perspectiva dos Estudos Culturais. Petrópolis: Vozes, 2000. 